\title{
Effect of one-day training on Knowledge related to Biosafety and waste management among life-science Students
}

Pranav Keshan ${ }^{1}$, Aayushi Rastogi ${ }^{2}$, Sunita Aggarwal ${ }^{3}$, Arti Nigam ${ }^{4}$, Rachna Kapila ${ }^{5}$, Sabin Syed ${ }^{6}$,

${ }^{1}$ Program Associate, Project ECHO, Institute of Liver and Biliary Science, New Delhi - 110070; ${ }^{2}$ PhD Scholar, Department of Epidemiology, Institute of Liver and Biliary Science, New Delhi - 110070; ${ }^{3}$ Associate Professor, Department of Microbiology, Institute of Home Economics, University of Delhi -110016; ${ }^{4}$ Associate Professor, Department of Microbiology, Institute of Home Economics, University of Delhi-110016; ${ }^{5}$ Associate Professor, Department of Biology, Institute of Home Economics, University of Delhi-110016; ${ }^{6}$ Program Coordinator, Project ECHO, Institute of Liver and Biliary Science, New Delhi- 110070

\begin{tabular}{|c|c|c|c|c|c|c|c|c|}
\hline Abstract & Introduction & Methodology & Results & Conclusion & References & Citation & \multicolumn{2}{|c|}{ Tables / Figures } \\
\hline \multicolumn{9}{|c|}{ Corresponding Author } \\
\hline \multicolumn{8}{|c|}{$\begin{array}{l}\text { Dr. Sabin Syed, Program Coordinator, Project ECHO, Institute of Liver and Biliary Science, New } \\
\text { Delhi }-110070 \\
\text { E Mail ID: sabin2012@gmail.com }\end{array}$} & 回语回 \\
\hline
\end{tabular}

\section{Citation}

Keshan P, Rastogi A, Aggarwal S, Nigam A, Kapila R, Syed S. Effect of one-day training on Knowledge related to Biosafety and waste management among life-science Students. Indian J Comm Health. 2020;32(4):694-698. https://doi.org/10.47203/IJCH.2020.v32i04.014

Source of Funding: Nil Conflict of Interest: None declared

\section{Article Cycle}

Received: 03/12/2020; Revision: 09/12/2020; Accepted: 23/12/2020; Published: 31/12/2020

This work is licensed under a Creative Commons Attribution 4.0 International License.

\section{Abstract}

Context: Laboratory workers are at increased risk of occupational hazards especially microbial infections. These occupational hazards can be reduced by merely creating awareness related to Biosafety. Thus biosafety and waste management training is important and needs to be inculcated at novice stage. Aims: The present study aimed to assess the effect of one-day training program on knowledge related to biosafety and biohazard among life-science students. Settings and Design: The study was conducted through online medium, organized by Department of Microbiology, Institute of Home Economics, University of Delhi using a Quasi Experimental design. Methods and Material: A one-day training on Biosafety and Waste Management was organized by Department of Microbiology for life-science students. A pre-test with 15 questions was administered to the participants before commencement of the training. One mark was allotted for each correct response and zero marks for incorrect marks. At the end of training, post knowledge was assessed using the same questions as pre-test. Statistical analysis used: The data on pre-post knowledge assessment was analyzed using SPSS Version 21. Paired t-test was used to assess the mean difference in pre and post knowledge assessment amongst the participants. The level of significance was taken as $<0.05$. Results: A total of 81 participants was analyzed for pre-post analysis. The mean age was $19.98 \pm 1.06$ years with $59(72.8 \%)$ being females. The mean pre-knowledge and post-knowledge score was found to be $10.20 \pm 2.09$ and $14.02 \pm 1.63$ respectively. The mean difference of $3.83 \pm 2.23$ in pre and post knowledge was found to be significant $(p<0.001)$. Conclusions: Life-science students have poor-to-moderate knowledge about biosafety and waste management. Training on biosafety helps in improving knowledge.

\section{Keywords}

Biosafety, Laboratory Workers, Occupational Health, Pre-Post, Waste Management. 
Key Messages: The one-day training on Bio Safety and Waste Management among life sciences students through online medium was able to assess the change in knowledge related to biosafety and showcased the improvement in knowledge post training.

\section{Introduction}

Laboratory workers are persistently exposed to a wide array of biological, chemical and physical occupational hazards especially several microbial infections such as Hepatitis viruses, Human Immunosuppressant Virus (HIV), Mycobacterium tuberculosis and several others $(1,2)$. These infections can cause life-threatening diseases and can cause life-long disability to the infected. Further, the risk associated with the exposed substances may not be realized immediately, rather until the occurrence of some unforeseen illness or accident. Also, few of these microbial infections are associated with stigma and discrimination. In addition to microbial infections, chemical agents, gases and solvents also carry the risk of occupational hazards as these agents can be explosive, inflammable or toxic and can result in fire, gassings and explosions in laboratories if not handled adequately (3).

The exposure to occupational hazards arises primarily due to the way the laboratory workers handle the routine work and the precautions taken by the workers in the laboratory (4). It has been found that approximately $66 \%$ of the laboratory workers are exposed to at least one type of biological hazard, most commonly being bacteria and parasites while working in laboratory (1). In addition to this, risk of exposure increases based upon the insufficient and inadequate biosafety arrangements available in the laboratory such as availability of biosafety cabinets, safety manuals and presence of safety kits in laboratory.

Apart from this, the most important is knowledge and awareness about occupational hazards in laboratories and practical measures to address these in case of mis happening $(4,5)$. The lack of awareness regarding biosafety matters results in inappropriate handling and hazardous laboratory practices during sample collection, processing, and discarding of specimens, potentially resulting in increased exposure to pathogens among laboratory technicians. However, familiarity and use of universal work precautions while handling blood and bodily fluid as well as other contagious samples can help in reducing the exposure to pathogens in laboratory settings(6). However, studies have reported poor to moderate knowledge about occupational health and safety among laboratory technicians (7).

Poor knowledge can be enhanced by providing trainings and educating the laboratory staff on good laboratory practices on a regular basis (8). Furthermore, if these trainings are provided to students who are potentially going to work in laboratories, can have much better impact. With this, a one-day training on Biosafety and Waste Management was organized among the life-science undergraduate students to educate them about common biohazards in laboratory settings and various biosafety practices to address them.

\section{Aims \& Objectives}

To assess the effect of one-day training program on knowledge related to Biosafety and biohazard among life-science students.

\section{Material \& Methods}

A one-day training on 'Biosafety and Waste Management' was conducted to impart training about common biohazards in laboratory settings and various biosafety practices along with waste management in laboratory setting among lifesciences undergraduate students by Department of Microbiology, Institute of Home Economics (IHE), University of Delhi under the aegis of DBT Star College Scheme and IQAC.

The scientific agenda was finalized by the speaker in consultation with the faculties of the Department of Microbiology, IHE. Following finalization of the training agenda, a link to Google meet was created for online training. The e-brochure of the training was circulated with the faculty members of lifesciences such as Microbiology, Biochemistry, Biomedical sciences in different colleges of Delhi University. The participants have to pre-register themselves for attending the online training.

Before the commencement of the training, a preassessment of knowledge was done after taking the informed consent from the participants via sharing an online link on Google form. The pre-assessment questionnaire consisted of demographic details along with 15 multiple-choice questions related to knowledge of Biosafety and Waste Management. Each question was of one-mark, making the total score to be 15. A participant was allotted one mark for each correct response and zero marks for 
incorrect marks. Following assessment of knowledge, the training on scientific sessions continued as per the schedule through online mode. The training program was divided into two sessions of 75 minutes each: i) Biosafety Levels and ii) Biosafety and Waste Management. The queries of the participants were addressed in detail by the speaker at the end of each sessions. At the end of the scientific sessions link of the post assessment questionnaire was shared with all the participants on the same online platform. The online post-test questionnaire consisted of the same questions as pre-test.

The data on pre-post knowledge assessment was extracted in MS Excel from Google forms and was analyzed using SPSS Version 21. The continuous data was summarized as mean and standard deviation whereas categorical data was summarized as frequencies with percentages. Independent t-test was used to assess the mean knowledge score across various demographic variables. The paired t-test was used to assess the mean difference in pre and post knowledge assessment amongst the participants. The level of significance was taken as $<0.05$

\section{Results}

A total of 104 participants attended the training including the faculty members. However, we included only 81 life science students in the pre-post analysis as remaining observations were either incomplete $(n=5)$ or have not filled posttest $(n=12)$ or filled by faculty members $(n=6)$. The mean age of the included participants was $19.98 \pm 1.06$ years and of the total participants, 59 (72.8\%) were female. Approximately, $18.5 \%$ of the total participants $(n=15)$ have attended such training in past (Table 1$)$. Of the total participants who attended such trainings in past, approximately $67 \%$ of the participants $(n=10)$ have attended such training within 6 months.

The training demonstrated increase in knowledge levels of the attendees. The mean pre-knowledge score was found to be $10.20 \pm 2.09$ out of 15 whereas the mean post-knowledge score was found to be $14.02 \pm 1.63$ out of 15 . The paired t-test between the pre and post knowledge score suggested a mean difference of $3.83 \pm 2.23$. This difference in pre and post knowledge score was found to be significant $(p<0.001)$. The respondents had moderate preknowledge with average correct response of $68 \%$, ranging from $39.51 \%$ to $98.78 \%$ whereas post- knowledge was good with $93.5 \%$ correct response, ranging from $83.95 \%$ to $100 \%$ (Table 2).

The study suggested there was no statistically significant difference in mean pre and post knowledge score with respect to demographic characteristics. No statistical significance could be identified in mean change in knowledge score with respect to demographic factors (Table 3 ).

\section{Discussion}

Laboratory workers are at increased risk of occupational hazards especially microbial infections. These occupational hazards can be reduced by merely creating awareness related to Biosafety. Thus biosafety and waste management training is important and needs to be learnt by the laboratory workers. Thus, with this background, Department of Microbiology, IHE organized a one-day training on Biosafety and Waste Management for the novice life-science students who will be potentially working in such laboratories in near future. The present study assessed the effect of one-day training program on knowledge related to Biosafety and biohazard among life-science students.

The pre-knowledge was found to be $10.20 \pm 2.09$ out of 15 in life-sciences students which is poor-tomoderate. The findings are in line with the studies performed on in-service laboratory workers (7). Approximately $87.65 \%$ correctly identified the Personal protective equipment and its use as also emphasized by previous studies (8). In the present study, pre-knowledge related to questions dealing with blood spills was found to be poor as compared to an Indian Study (68.97\%) (8). This could be attributable to the fact that the current study is undertaken in undergraduate students who are less exposed to blood spill whereas the previous study was conducted among in-service laboratory technicians.

The post knowledge score was found to be $14.02 \pm$ 1.63 out of 15 . The mean difference between post and pre knowledge score is $3.83 \pm 2.23$, indicating an increase in knowledge level following a one-day training. Similar findings have been observed in previous studies (8). The maximum increase in score was seen in questions which were responded incorrectly in pre-test. This is attributable to the fact, that there was more scope of improvement as compared to questions with already correct responses in pre-test. 
One of the limitation of the study was its small sample size. There could have been a selection bias in the study as pre and post knowledge assessment was voluntary and not mandatory. Approximately data for $16 \%(n=17)$ of the total attendee can't be assessed because of either incomplete or missing entries of pre-post-test. Further, authors are not sure whether these $16 \%$ purposefully didn't fill the post test because of expecting low score or it was unintentional. The study could have also suffered a response-shift bias because of its pre-post design. In addition to this, the design by default is exposed to intrinsic bias; this is because participants are already exposed to the questions in the pre-test and this might have influence the post-test responses.

Despite these limitations, the study is one of its kind and one of the first study to assess the preknowledge related to biosafety of undergraduate life-science students. Moreover, the study was able to assess the change in knowledge related to biosafety and was able to showcase improvement in knowledge post training. Thus, more such trainings should be encourage among life-science students as well as in-service laboratory workers

\section{Conclusion}

Life-science students have poor-to-moderate knowledge about biosafety and waste management. Training on biosafety helps in improving knowledge.

\section{Recommendation}

It is recommended to conduct more awareness trainings on biosafety and bio medical waste management trainings among life science students to encourage better practices.

\section{Limitation of the study}

One of the limitations of the study was its small sample size. There could have been a selection bias in the study as pre and post knowledge assessment was voluntary and not mandatory. The study could have also suffered a response-shift bias because of its pre-post design. In addition to this, the design by default is exposed to intrinsic bias; this is because participants are already exposed to the questions in the pre-test and this might have influenced the posttest responses.

\section{Relevance of the study}

Our study is relevant to all life sciences students, specially professionals working in laboratories, as they are continuously exposed to infected environment. A high level of awareness regarding biosafety mechanisms and proper disposal of bio medical waste can play a vital role in preventing and controlling the health issues effectively.

\section{Authors Contribution}

PK, AR, SA, SS -conceived the idea, designed the study and gathered the relevant data. AR, AN, RK, SS contributed in defining intellectual content. PK analyzed the data. PK, AA, SS prepared the manuscript. PK, AR, SA, AN, RK, SS edited and reviewed the manuscript and performed the literature search.

\section{References}

1. Tait FN, Mburu C, Gikunju J. Occupational safety and health status of medicallaboratories in Kajiado County, Kenya. Pan Afr Med J. $2018 \quad$ 23;29:65. doi:10.11604/pamj.2018.29.65.12578. PMID: 29875946; PMCID: PMC5987110.[PubMed].

2. Zaveri, J. \& Karia, J. Knowledge, attitudes and practice of laboratory technicians regarding universal work precaution. Natl. J. Med. Res. 2, 113-115 (2012).

3. Pohanish, R. P. \& Greene, S. A. Wiley guide to chemical incompatibilities. (John Wiley \& Sons, 2009).

4. Sewunet T, Kebede W, Wondafrash B, Workalemau B, Abebe G. Survey of safety practices among hospital laboratories in Oromia Regional State, Ethiopia. Ethiop J Health Sci. 2014;24(4):307-10. PMID: 25489194; PMCID: PMC4248029.[PubMed].

5. Shekhar, H., Patel, M., Jain, C., Garg, N. \& Mangukiya, K. Awareness to health hazards and biosafety precautions among laboratory technicians working in tertiary-care center in Rajasthan, India -. Int. J. Med. Sci. Public Health 4, 15-18 (2015).

6. Directorate General Factory Advice Service and Labour Institutes \& International Labour Organization (ILO). National Occupational Safety and Health (OSH) Profile. (2015).

7. MD, Senior Resident at Saudi Board for Community Medicine \& Preventive Medicine, Jeddah, Kingdom of Saudi Arabia \& Al-Zahrani, D. K. M. Assessment of Biosafety and associated Occupational Hazards among Laboratories Health Workers in Governmental Moderate and High Complexity Medical Labs (Jeddah, 2018). J. Med. Sci. Clin. Res. 6, (2018).

8. Goswami, H., Soni, S., Patel, S. M., Patel, M. \& Apartments, V. A study on knowledge, attitude and practice of laboratory safety measures among paramedical staff of laboratory services. undefined /paper/A-STUDY-ONKNOWLEDGE\%2C-ATTITUDE-AND-PRACTICE-OF-OFGoswami-

Soni/4fae4134e92fbd13aaf529679cdbc26f1e229530 (2011). 


\section{Tables}

TABLE 1 BASELINE CHARACTERISTICS OF THE PARTICIPANTS ( $\mathrm{N}=81$ )

\begin{tabular}{|l|c|}
\hline Factor & $\mathbf{n}(\%)$ \\
\hline Mean Age \pm SD & $19.98 \pm 1.06$ \\
\hline Gender & $22(27.2)$ \\
\hline Male & $59(72.8)$ \\
\hline Female & $24(29.6)$ \\
\hline Qualification & $57(70.4)$ \\
\hline $2^{\text {nd }}$ year student & $15(18.5)$ \\
\hline $3^{\text {rd }}$ year student & $66(81.5)$ \\
\hline Attended such training in past & \\
\hline Yes & \\
\hline No & \\
\hline SD :Standard deviation & \\
\hline
\end{tabular}

TABLE 2 KNOWLEDGE ABOUT LABORATORY SAFETY AMONG PARTICIPANTS ( $\mathrm{N}=81$ )

\begin{tabular}{|l|l|c|c|}
\hline Qno & Questions & $\begin{array}{c}\text { Pre-test Correct } \\
\text { Responses (\%) }\end{array}$ & $\begin{array}{c}\text { Post-test Correct } \\
\text { Responses (\%) }\end{array}$ \\
\hline Q1 & PPE stands for & $78(96.3)$ & $76(93.83)$ \\
\hline Q2 & $\begin{array}{l}\text { Which of the following statements about Personal Protective Equipment } \\
\text { (PPE) are correct? }\end{array}$ & $71(87.65)$ & $79(97.53)$ \\
\hline Q3 & $\begin{array}{l}\text { Which of the following practices should be utilized when working in a } \\
\text { biological safety cabinet? }\end{array}$ & $80(98.77)$ & $78(96.3)$ \\
\hline Q4 & Which of the following practices are allowed in the laboratory? & $79(97.53)$ & $81(100)$ \\
\hline Q5 & Bleach should always be used to sterilize lab instruments after cleaning & $53(65.43)$ & $68(83.95)$ \\
\hline Q6 & Handling of HIV, H1N1, Yersinia Pestis samples require Biosafety level: & $40(49.38)$ & $74(91.36)$ \\
\hline Q7 & $\begin{array}{l}\text { Specified different levels of biocontainment which ranges from Biosafety } \\
\text { level 1 (BSL-1) to Biosafety level (BSL-4) have been proposed by: - }\end{array}$ & $32(39.51)$ & $78(96.3)$ \\
\hline Q8 & HEPA filters are & $70(86.42)$ & $71(87.65)$ \\
\hline Q9 & Which of the following set of pathogens require BSL 4 for manipulation: & $62(76.54)$ & $77(95.06)$ \\
\hline Q10 & $\begin{array}{l}\text { Which of the following is NOT the correct set of personal protective } \\
\text { equipment? }\end{array}$ & $52(64.2)$ & $79(97.53)$ \\
\hline Q11 & To clean blood spills which of the following could be used? & $47(58.02)$ & $78(96.3)$ \\
\hline Q12 & In case of a needle stick injury immediately & $37(45.68)$ & $74(91.36)$ \\
\hline Q13 & $\begin{array}{l}\text { Which of the following ministry is responsible for making regulations for } \\
\text { management of Bio Medical Waste in India? }\end{array}$ & $34(41.98)$ & $71(87.65)$ \\
\hline Q14 & $\begin{array}{l}\text { Minimum contact time of disinfectant with the surface while managing } \\
\text { blood spill is }\end{array}$ & $32(39.51)$ & $77(95.06)$ \\
\hline Q15 & While performing hand hygiene, the time recommendations:- & $59(72.84)$ & $75(92.59)$ \\
\hline & Overall & $826(68)$ & $1136(93.5)$ \\
\hline
\end{tabular}

TABLE 3 ASSOCIATION BETWEEN KNOWLEDGE SCORE AND DEMOGRAPHIC CHARACTERISTICS

\begin{tabular}{|c|c|c|c|c|c|c|}
\hline & Pre-test & p-value & Post-test & p-value & $\begin{array}{c}\text { Change in knowledge } \\
\text { B-coeff }(95 \% \mathrm{Cl})\end{array}$ & p-value \\
\hline Age & & & & & $0.02(-0.51-0.05)$ & 0.95 \\
\hline $\begin{array}{l}\text { Gender } \\
\text { Male } \\
\text { Female }\end{array}$ & $\begin{array}{l}10.73 \pm 1.98 \\
10.00 \pm 2.11\end{array}$ & 0.166 & $\begin{array}{l}14.18 \pm 1.14 \\
13.97 \pm 1.79\end{array}$ & 0.600 & $\begin{array}{c}\text { Ref } \\
0.50(-0.64-1.64)\end{array}$ & 0.38 \\
\hline $\begin{array}{l}\text { Qualification } \\
2^{\text {nd }} \text { year student } \\
3^{\text {rd }} \text { year student }\end{array}$ & $\begin{array}{l}10.08 \pm 1.97 \\
10.24 \pm 2.15\end{array}$ & 0.752 & $\begin{array}{l}13.58 \pm 2.50 \\
14.21 \pm 1.06\end{array}$ & 0.116 & $\begin{array}{c}\text { Ref } \\
0.39(-0.83-1.61)\end{array}$ & 0.52 \\
\hline $\begin{array}{l}\text { Attended such training in past } \\
\text { Yes } \\
\text { No }\end{array}$ & $\begin{array}{l}10.33 \pm 2.10 \\
10.16 \pm 2.09\end{array}$ & 0.783 & $\begin{array}{l}14.06 \pm 1.72 \\
13.87 \pm 1.25\end{array}$ & 0.681 & $\begin{array}{c}\text { Ref } \\
-0.39(-1.69-0.91)\end{array}$ & 0.55 \\
\hline
\end{tabular}

